\title{
Generation of Azotobacter vinelandii strains defective in siderophore production and characterization of a strain unable to produce known siderophores
}

\author{
M. Serdal Sevinc and William J. Page* \\ Department of Microbiology, University of Alberta, Edmonton, Alberta, Canada T6G 2E9
}

(Received 30 July 1991; revised 7 November 1991; accepted 20 November 1991)

\begin{abstract}
Siderophore-negative mutants of Azotobacter vinelandii were generated by insertional mutagenesis with a Tn5 construct containing a promoterless $\operatorname{lux} A B$ fusion. The use of this construct, delivered on a suicide plasmid by conjugation, allowed the selection of mutations in iron-repressible genes by virtue of the expression of ironregulated bioluminescence. Although many iron-regulated mutants were selected, only a few could be easily identified as defective in siderophore production. These included a non-fluorescent azotobactin-negative phenotype (strain D27), and strain F196, which had lost the ability to produce the catechol siderophores azotochelin and aminochelin as well as the lower-affinity chelator 2,3-dihydroxybenzoic acid. Strain D27 had normal production of catechol siderophores; while strain F196 produced 2.5 times as much azotobactin as the wild-type. Two other mutants demonstrated normal catechol levels and either low or relatively unrepressed azotobactin levels. Transformation of the DNA from strain F196 into another spontaneously obtained azotobactin-negative strain (UA1) resulted in strain P100, which was unable to produce the known siderophores. Unlike the wild-type and other siderophore-deficient mutants, this strain was unable to grow in the presence of the iron chelator ethylenediamine di-(o-hydroxyphenylacetic acid) (EDDHA; $50 \mu \mathrm{g} \mathrm{ml}^{-1}$ ) unless stored iron was carried over in the inoculum. Strain P100 did grow on iron-limited medium containing EDDHA when the catechol or azotobactin siderophores were provided exogenously. However, strain $\mathrm{P} 100$ gave a positive result in the chrome azurol-S assay (CAS), a non-specific assay for siderophores. The CAS activity was iron-repressible and strain P100 was able to grow and accumulate more iron from the insoluble iron minerals $\mathrm{FeS}$, vivianite and $\mathrm{Fe}_{3} \mathrm{O}_{4}$ than was available by simple diffusion or exchange. Therefore, it appears that iron-limited $A$. vinelandii produces an as yet unidentified low-affinity non-conventional (non-catechol, non-hydroxamate) siderophore.
\end{abstract}

\section{Introduction}

Almost all organisms require iron for survival. However, under aerobic, neutral $\mathrm{pH}$ growth conditions soluble iron is rapidly oxidized and forms extremely insoluble oxides and oxyhydroxides (Neilands, 1981). Most aerobic and facultative organisms must scavenge trace amounts of soluble iron and have to transport it into the cell by the production of small, soluble, high-affinity $\mathrm{Fe}(\mathrm{III})$ coordinating ligands, the siderophores (Neilands, 1981). The production of siderophores and the specific transport of iron into the ligand-producing cell is an important

\footnotetext{
* Author for correspondence. Tel. (403) 492 4782; fax (403) 4922216.

Abbreviations: CAS, chrome azurol-S; 2,3-DHBA, 2,3-dihydroxybenzoic acid; EDDHA, ethylenediamine di-(o-hydroxyphenylacetic acid); IROMP, iron-regulated outer-membrane protein.
}

adaptation for survival and success in a variety of ironlimited environments (Cox, 1989; Neilands, 1982).

Azotobacter vinelandii is an obligate aerobe that is capable of aerobic nitrogen fixation. The organism uses its extremely high respiratory rate to consume oxygen and protect the oxygen-labile nitrogenase (Robson \& Postgate, 1980). Such a high respiratory activity generates toxic oxygen radicals that are destroyed by active catalase and superoxide dismutase (Jurtshuk et al., 1984). All of these activities are dependent on an adequate supply of iron. Upon growth in iron-limited medium, $\boldsymbol{A}$. vinelandii produces a pyoverdin-type siderophore, azotobactin (Demange et al., 1986; Page et al., 1991) and two catechol-type siderophores, azotochelin (Corbin \& Bulen, 1969) and aminochelin (Page \& von Tigerstrom, 1988). Furthermore, 2,3-dihydroxybenzoic acid (2,3DHBA) appears to be produced as a low-affinity iron 
chelator that solubilizes iron and facilitates low-affinity constitutive iron uptake (Page \& Huyer, 1984).

The production of siderophores by $A$. vinelandii follows a sequential induction pattern. As iron becomes limiting $\left(\approx 7 \mu \mathrm{M}-\mathrm{Fe}^{3+}\right)$ the catechol siderophores are produced coordinately (Page \& von Tigerstrom, 1988). If iron continues to be limiting $\left(\leq 3 \mu \mathrm{M}-\mathrm{Fe}^{3+}\right)$, then azotobactin is formed (Page \& von Tigerstrom, 1988). When iron is supplied to the cells, azotobactin is repressed first, followed by the catechols, until 2,3-DHBA remains as the sole ligand (Page \& Huyer, 1984). In enteric bacteria, iron repression is mediated by the association of a repressor protein (Fur) with intracellular $\mathrm{Fe}^{2+}$ and specific promoter sequences (de Lorenzo et al., 1987). The pattern of sequential siderophore regulation is not seen in enteric bacteria (McIntosh \& Earhardt, 1977), which suggests that in $A$. vinelandii iron-repressible genes may be regulated by a different mechanism or that the interaction of the Fur- $\mathrm{Fe}^{2+}$ complex with iron-repressible promoters may be affected by promoter affinity or other factors (Page \& Patrick, 1988).

A first step in studies of iron regulation in $A$. vinelandii is the generation of mutants defective in iron-regulated gene activity. Transposon mutagenesis, using a derivative of $\operatorname{Tn} 5$ containing a promoterless $\operatorname{lu} x A B$ fusion, has been used in this study to generate $A$. vinelandii strains defective in siderophore production. Tn 5 was delivered on a suicide vector ( $\mathrm{p} \operatorname{Tn} 5 \operatorname{lux}$ ), so that $\operatorname{Tn} 5$ would only persist in cells where transposition into the chromosome had occurred and bioluminescence (Lux) activity would be under the control of chromosomal promoters (Berg $e t$ $a l ., 1989)$. This provides an easy screening method to obtain mutations in iron-regulated genes, especially when selection based on iron-regulated natural phenotypes is difficult.

\section{Methods}

Bacterial strains and growth conditions. The capsule-negative parent A. vinelandii strain UW (strain OP; ATCC 13705) and its spontaneously produced azotobactin-negative derivative UAl (Page \& Huyer, 1984) were maintained on iron-sufficient Burk's medium (BBGN): $0.81 \mathrm{~mm}-\mathrm{MgSO}_{4}, 0.58 \mathrm{mM}-\mathrm{CaSO}_{4}, 5 \mu \mathrm{M}-\mathrm{Na}_{2} \mathrm{MoO}_{4}$ and $25 \mu \mathrm{M}$-ferric citrate in $5.0 \mathrm{~mm}$-potassium phosphate buffer (pH 7.2) with $1 \%(\mathrm{w} / \mathrm{v})$ glucose, $14 \mathrm{~mm}$-ammonium acetate and $1.8 \%(\mathrm{w} / \mathrm{v})$ agar. Nitrogen-free iron-sufficient medium (BBG) was of the same composition without added ammonium acetate. Iron-limited Burk's medium contained no added ferric citrate (OFeBBGN or $0 \mathrm{FeBBG}$ ), but contained about $0.5 \mu \mathrm{M}$-iron contamination from medium components, or had $1 \mu \mathrm{M}$-ferric citrate added (as noted in Results) to promote ironlimited growth (Page \& von Tigerstrom, 1988). Burk's buffer was the same as Burk's medium without the added glucose and ammonium acetate. Liquid cultures $(100 \mathrm{ml}$ culture per $500 \mathrm{ml}$ Erlenmeyer flask) were inoculated with $1 \%(\mathrm{v} / \mathrm{v})$ inoculum and incubated at $30^{\circ} \mathrm{C}$ with rotary shaking at 225 r.p.m. In most cases, the inoculum was pregrown overnight in liquid iron-limited Burk's medium containing $1 \mu \mathrm{M}$-ferric citrate. In some cases, the iron chelator ethylenediamine di-(o-hydroxy- phenylacetic acid) (EDDHA) was added to a final concentration of $50 \mu \mathrm{g} \mathrm{ml}^{-1}$ to further limit iron availability.

Growth of $A$. vinelandii strains under aerobic nitrogen-fixing conditions was carried out in $500 \mathrm{ml}$ Erlenmeyer baffle flasks (each flask contained four radial indentations in its base) containing $100 \mathrm{ml}$ of medium. The flasks were incubated with shaking at 300 r.p.m. The inoculum was prepared in $0 \mathrm{FeBBGN}$, to minimize the carryover of stored iron (see Results).

Escherichia coli strain S17-1 ( pro $\mathrm{Res}^{-} \mathrm{Mod}^{+}$) containing the suicide plasmid pTn5luxAB (a gift of A. Szalay, Department of Plant Science, Faculty of Agriculture, University of Alberta ; Berg et al., 1989), and $E$. coli strain $\mathrm{HB} 101$ (supE44 hsdS20 $\left(\mathrm{r}_{\mathrm{B}}^{-} \mathrm{m}_{\bar{B}}^{-}\right)$recAl3 ara-14 proA2 lacYI galK2 rpsL20 xyl-5 mtl-l) containing the helper plasmid pRK2013 (Figurski \& Helinski, 1979) were grown at $37^{\circ} \mathrm{C}$ in TYE medium (tryptone, $15 \mathrm{~g} \mathrm{l}^{-1}$; yeast extract, $10 \mathrm{~g} \mathrm{l}^{-1} ; \mathrm{NaCl}, 5 \mathrm{~g} \mathrm{l}^{-}$; agar, $18 \mathrm{~g} \mathrm{l}^{-1}$ ) with $50 \mu \mathrm{g}$ kanamycin $\mathrm{ml}^{-1}$ for strain $\mathrm{HB} 101$ and $40 \mu \mathrm{g}$ ampicillin $\mathrm{ml}^{-1}$ for strain S17-1.

Mineral iron enclosed in dialysis bags and determination of iron concentration. In order to study the ability of $A$. vinelandii strains to solubilize iron from insoluble minerals and to have a mineral-free cell suspension for further analysis, crushed mineral $(50 \mathrm{mg}$, about 200 mesh) was first added to a $1 \mathrm{~cm}$ diameter, 10-14 kDa molecular mass cut-off dialysis tubing sac containing $2 \mathrm{ml}$ OFeBBGN, then the sealed bag was placed in $100 \mathrm{ml} 0 \mathrm{FeBBGN}$. Each mineral was prepared in duplicate flasks and sterilized by autoclaving. One flask was prepared $24 \mathrm{~h}$ in advance, incubated with shaking overnight, then the dialysis bag was aseptically removed. This flask served as a control for freely exchangeable iron (Page, 1987). The second flask, containing sterile medium and the dialysis bag, and the freely exchangeable iron control flask were inoculated with an iron-limited culture, pregrown overnight in OFeBBGN. After $24 \mathrm{~h}$ incubation at $30^{\circ} \mathrm{C}$ with shaking at 225 r.p.m., $75 \mathrm{ml}$ cell suspension was harvested by centrifugation and the cells were washed with $10 \mathrm{mM}$-sodium citrate $(\mathrm{pH} \mathrm{7.2)}$ to remove surface-bound iron. The cell pellet was suspended in $2.5 \mathrm{ml} 7 \%(\mathrm{w} / \mathrm{v})$ perchloric acid and extracted overnight at room temperature and for $4 \mathrm{~h}$ at $80^{\circ} \mathrm{C}$ prior to iron determination using a $2,2^{\prime}$-bipyridyl assay (Page \& Huyer, 1984). All glassware for these studies was acid washed (Collinson et al., 1987). Cell protein was determined as described by Page \& Huyer (1984).

Introduction of pTn5lux by conjugation and selection of transconjugants. Exponentially growing $A$. vinelandii and $E$. coli cells were mixed in approximately equal proportions after washing three times with ironlimited Burk's buffer (OFeBB). Matings were carried out directly on the surface of BBGN plates at $30^{\circ} \mathrm{C}$ without collecting the cells on a filter. At $24 \mathrm{~h}$ intervals the mixed culture was scraped from the plate, resuspended in $1-3 \mathrm{ml} 0 \mathrm{FeBB}$, and spread onto BBGN plates containing $10 \mu \mathrm{g}$ kanamycin $\mathrm{ml}^{-1}$ for the selection of transconjugants. Isolated $\mathrm{Kan}^{r}$ Azotobacter colonies were purified by streaking on BBGN plates containing kanamycin.

Detection of iron-repressible bioluminescence. Bioluminescence was detected by Petri plate contact printing using Kodak XAR-5 X-ray film. In comparisons of the bioluminescence of cells grown on ironlimited (Burk's medium containing $1 \mu \mathrm{M}$-ferric citrate) and ironsufficient (Burk's medium containing $300 \mu \mathrm{M}$-ferric citrate) medium on a single Petri plate, the bacteria were spotted (about 5-7 mm diameter) in duplicate onto the surface of the respective agar media contained in a Petri dish split in half by a plastic divider. One drop $(10 \mu 1)$ of n-decanal was spread on the lid of the Petri dish and the complete dish was placed agar-side-down on the film for $15 \mathrm{~min}$ to allow the bioluminescent spots to expose the film.

Detection of siderophores. Siderophores were detected in acidified ( $\mathrm{HCl}, \mathrm{pH} 1.8)$ culture supernatant fluids by measuring absorption at $310 \mathrm{~nm}$ for catechols and $380 \mathrm{~nm}$ for azotobactin (Page \& Huyer, 1984) 
using a Hitachi U-2000 recording spectrophotometer. Azotobactin contains a hydroxamate group contributed by $N^{\delta}$-hydroxyornithine (Demange et al., 1986), which was quantified by the method of Csaky (1948), with the hydrolysis step conducted at $100^{\circ} \mathrm{C}$ for $6 \mathrm{~h}$, as recommended, or for $1 \mathrm{~h}$ in the autoclave $\left(121^{\circ} \mathrm{C}, 1.1 \mathrm{~kg} \mathrm{~cm}^{-2}\right.$ pressure). Catechols were quantified by the methods of Barnum (1977). Citric acid was assayed enzymically with a kit obtained from Boehringer. Samples were concentrated 10 -fold by freeze-drying prior to the citrate assay.

Siderophore production also was detected using the chrome azurol-S (CAS) plating and CAS-shuttle colorimetric assays described by Schwyn \& Neilands (1987), except that Burk's medium was substituted for the MM9 salts/casamino acids medium. The CAS assay is a universal assay for the detection of siderophores and operates independently of the siderophore structure. The presence of an ironchelator (presumably a siderophore) is indicated by the decolorization of a blue-coloured ferric-CAS complex, resulting in a yellow-gold halo around colonies growing on CAS medium or as a result of mixing culture fluids in a tube assay. The shuttle assay contains $4 \mathrm{~mm}$ sulphosalicylic acid added to the reaction mixture to destabilize the ferric-CAS complex and accelerate ferric exchange to the siderophore (Schwyn \& Neilands, 1987). The CAS shuttle assay was initiated by the addition of $0.5 \mathrm{ml}$ culture supernatant fluid to $0.5 \mathrm{ml}$ of the CAS shuttle solution. This was immediately mixed and placed in a Hitachi U-2000 spectrophotometer and the decrease in absorption at $630 \mathrm{~nm}$ was recorded over $\geq 2 \mathrm{~min}$. The end-point of the reaction was the time at which no further decolorization of the CAS complex was observed. Total siderophore activity (TSA) was calculated from the initial rate of decolorization, where one unit of activity was a decrease in $A_{620}$ of $0.001 \mathrm{~s}^{-1}$. The total siderophore specific activity was calculated as the TSA units (mg cell protein) $)^{-1}$ present in $0.5 \mathrm{ml}$ culture.

Catechol siderophores in the acidified culture supernatant fluid were extracted into ethyl acetate and visualized by thin-layer chromatography on silica gel $\mathrm{G}$ (Brinkmann), using a benzene/acetic acid/ water (125:72:3, by vol.) solvent system and detection with $2,2^{\prime}-$ dipyridyl-ferric chloride (Krebs et al., 1969). Aminochelin was demonstrated as residual material absorbing at $310 \mathrm{~nm}$ in the aqueous phase after ethyl acetate extraction and as material absorbing at $310 \mathrm{~nm}$ that could be extracted with butanol (Page \& von Tigerstrom, 1988).

When the siderophore activity of ethyl-acetate-extracted culture fluids was tested by the CAS-shuttle assay, the ethyl acetate fraction was air dried and dissolved in distilled water and the ethyl acetate in the aqueous phase was allowed to evaporate overnight. All fluids were adjusted to $\mathrm{pH} 6.0$ before the CAS-shuttle assay. Ethyl acetate and ethanol were found to give false positive results in this assay, but 10 -fold concentrated iron-limited medium did not produce interference.

Demonstration of iron-repressible outer membrane proteins (IROMPs). A. vinelandii was grown overnight in iron-limited (1 $\mu \mathrm{M}$-ferric citrate) and iron-sufficient (50 $\mu \mathrm{M}$-ferric citrate) Burk's medium. The cells were harvested by centrifugation and broken by sonication as described by Page \& Huyer (1984). Outer membranes were prepared by extraction with Sarcosyl (Filip et al., 1973; Page \& Huyer, 1984) and examined by SDS-polyacrylamide gel electrophoresis as described previously (Page $\&$ von Tigerstrom, 1982). The outer membrane proteins in the gel ( $20 \mu \mathrm{g}$ per lane) were visualized with the silver stain of Wray et al. (1981).

Transformation of $A$. vinelandii. Chromosomal DNA was purified as described by Wilson (1990). Transformation and competence development conditions for $\boldsymbol{A}$. vinelandii were as described by Page $\&$ von Tigerstrom (1979), except that the incubation time of $20 \mathrm{~h}$ for enrichment of the phenotype was not necessary, as previously noted (Doran et al., 1987).

\section{Results}

\section{pTn5luxAB mutagenesis of $A$. vinelandii}

The plasmid pTn5luxAB does not encode transfer functions and would normally be mobilized by a helper plasmid in heterologous matings. However, transconjugants were not obtained in short-term matings (up to $24 \mathrm{~h}$ ) using traditional procedures (Selveraj \& Iyer, 1983). A few transconjugants were observed after $2-3 \mathrm{~d}$ of mating when triparental matings were conducted directly on the surface of the BBGN plates. However, the frequency of plasmid transfer was increased by mixing only the donor $E$. coli with the recipient $A$. vinelandii, without the helper plasmid. Clearly pTn5luxAB was not being transferred by normal conjugation. The frequency of plasmid transfer could not be accurately determined, because many of the $\mathrm{Kan}^{\mathrm{r}} A$. vinelandii isolates were undoubtedly identical clones which arose during the long incubation period.

Over $500 \mathrm{Kan}^{\mathrm{r}}$ strains were generated by repeated transfers of pTn5luxAB to $A$. vinelandii $\mathrm{UW}$. Because the plasmid was not maintained in $A$. vinelandii, stable $\mathrm{Kan}^{\mathrm{r}}$ strains were assumed to be the result of $\mathrm{Tn} 5$ transposition into the chromosome. Screening the strains for ironrepressible bioluminescence categorized the strains into four groups: (i) those that were not bioluminescent (very frequent); (ii) those that expressed constitutive strong bioluminescence (rare); (iii) those that expressed moderately repressible bioluminescence (very frequent); and (iv) those that expressed strongly regulated bioluminescence (frequent). All the $\mathrm{Kan}^{\mathrm{r}}$ strains were stable and did not lose antibiotic resistance or Lux activity, even after transfer under nonselective conditions.

The $\mathrm{Kan}^{\mathrm{r}}$ strains expressing iron-regulated bioluminescence (about 100 strains including some identical clones) were immediately tested on CAS medium plates in an attempt to detect siderophore-negative strains, siderophore overproduction, or siderophore transport deficiencies as described by Schwyn \& Neilands (1987). In all cases, the haloes around the spots of bacterial growth (indicating deferration of the ferric complex in the medium) were normal (within the limits of experimental error).

However, since $A$. vinelandii normally produced multiple siderophores, CAS screening was likely to be too imprecise to detect a deficiency in a single siderophore. Therefore, the culture supernatant fluids of cultures grown overnight in iron-limited $(0$ and $1 \mu \mathrm{M}$ ferric citrate) and iron-sufficient (10 and $50 \mu \mathrm{M}$-ferric citrate) medium were scanned spectrophotometrically to detect catechols $\left(A_{310}\right)$ and azotobactin $\left(A_{380}\right)$. The vast majority of the strains demonstrated absorption per cell protein values identical to the wild-type (within the 
Table 1. Characterization of siderophore-negative strains

All strains were grown for $24 \mathrm{~h}$ at $30^{\circ} \mathrm{C}$ in iron-limited ( $1 \mu \mathrm{M}$-ferric citrate) medium. All values are means of at least two duplicates.

\begin{tabular}{|c|c|c|c|c|c|c|c|}
\hline \multirow[b]{2}{*}{ Strain } & \multirow[b]{2}{*}{$\begin{array}{l}\text { Protein } \\
\left(\mu \mathrm{g} \mathrm{ml}^{-1}\right)\end{array}$} & \multirow[b]{2}{*}{$\begin{array}{l}\text { Iron-repressible } \\
\text { Lux activity }\end{array}$} & \multicolumn{2}{|c|}{ Hydroxamate } & \multicolumn{2}{|c|}{ Catechol } & \multirow{2}{*}{$\begin{array}{l}\text { Cellular iron } \\
\text { [ng (mg } \\
\left.\text { protein })^{-1}\right]\end{array}$} \\
\hline & & & $A_{380} *$ & $\underset{\left.\text { protein) }{ }^{-1}\right] \dagger}{[\mu \mathrm{g}(\mathrm{mg}}$ & $A_{310} *$ & 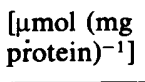 & \\
\hline UW & 389 & NA & $2 \cdot 83$ & $1.63(1.61)$ & $3 \cdot 24$ & $1 \cdot 48$ & 210 \\
\hline D27 & 310 & No & 0 & $\begin{array}{ll}0 & (0)\end{array}$ & $2 \cdot 75$ & $1 \cdot 38$ & 202 \\
\hline UAl & 402 & NA & 0 & $0 \quad(0)$ & $3 \cdot 31$ & 1.59 & 223 \\
\hline F196 & 348 & Yes & $6 \cdot 96$ & $4 \cdot 06(4 \cdot 26)$ & 0 & 0.04 & 209 \\
\hline P100 & 229 & Yes & 0 & $\begin{array}{ll}0 & (0)\end{array}$ & 0 & 0.03 & 197 \\
\hline
\end{tabular}

NA, Not applicable.

* Absorption of acidified supernatant fluids per mg cell protein present per ml culture.

+ Hydrolysis was conducted for $1 \mathrm{~h}$ in the autoclave or for $6 \mathrm{~h}$ at $100^{\circ} \mathrm{C}$ (values in parentheses). Units are $\mu \mathrm{g}$ hydroxylamine equivalents $\mathrm{ml}^{-1}$.

limits of experimental error). However, three strains (F196, F174, F124; probably identical clones) did not form any catechols and two other strains demonstrated normal catechol formation, but low (E21) or relatively unrepressed (F130) azotobactin formation. In addition, a strain that was unable to form azotobactin (D27) was detected amongst the non-bioluminescent strains by its failure to show fluorescence under $366 \mathrm{~nm}$ UV illumination. No differences were detected in the production of IROMPs by the wild-type strain and these mutant strains.

Strain F196 was grown in iron-limited medium containing $500 \mu \mathrm{M}-2,3-\mathrm{DHBA}$ and the resulting culture supernatant fluid was acidified and extracted with ethyl acetate. All of the catechol was extracted into ethyl acetate and all of this was determined to be 2,3-DHBA by thin-layer chromatography. Therefore, it appears that the failure of strain F196 to form the catechol siderophores cannot be reversed by the addition of 2,3-DHBA as a precursor.

\section{Generation of the pyoverdin-negative, catechol-negative strain P100}

A siderophore-negative strain of $A$. vinelandii could be a very useful tool for the study of siderophore-mediated iron-uptake, for use in a bioassay to detect mutant siderophores and to examine the importance of iron accumulation on cell activities. Such a strain was constructed by transfer of chromosomal DNA from strain F196 to the spontaneously generated azotobactinnegative strain UA1 by transformation and the selection of $\mathrm{Kan}^{\mathrm{r}}$ colonies. Almost all of the transformants were phenotypically identical (failure to show fluorescence under UV light, whitish colony colour, small size). One transformant was picked and designated strain P100. This strain showed no trace of azotobactin or catechols in spectrophotometric scanning.

\section{Siderophore production by siderophore-negative strains}

The production of catechols and hydroxamates by the strains was determined quantitatively (Table 1). The azotobactin-negative strains, D27 and UA1, did not produce hydroxamate and produced normal amounts of catechol. On the other hand, the catechol-negative strain, F196 (and its identical clones, data not shown), produced 2.5 times as much of the hydroxamate azotobactin as the parent strain. The low level of catechol detected in the normal or 10-fold concentrated culture fluids of strains F196 and P100 could not be extracted with ethyl acetate, was not detectable by thinlayer chromatography, and could not be extracted with butanol. This amount of catechol corresponded to an absorbance value of 0.004 , essentially at the limit of detection and within background values. Strains that lacked a single type of siderophore were not greatly impaired in their ability to grow, and accumulated iron to an extent comparable to the wild-type strain (Table 1). Strain P100 grew to about $59 \%$ of the wild-type value, but accumulated about $94 \%$ of the iron per cell protein found in the wild-type strain. Thus strain P100 appeared capable of iron accumulation from iron-limited medium, but this was less efficient than that of the other strains, hence overall growth was limited.

\section{Inhibition of growth of strain P100 with EDDHA}

Strains UW, D27, F196 and UA1 grew equally well in the iron-sufficient BBGN medium alone or containing 

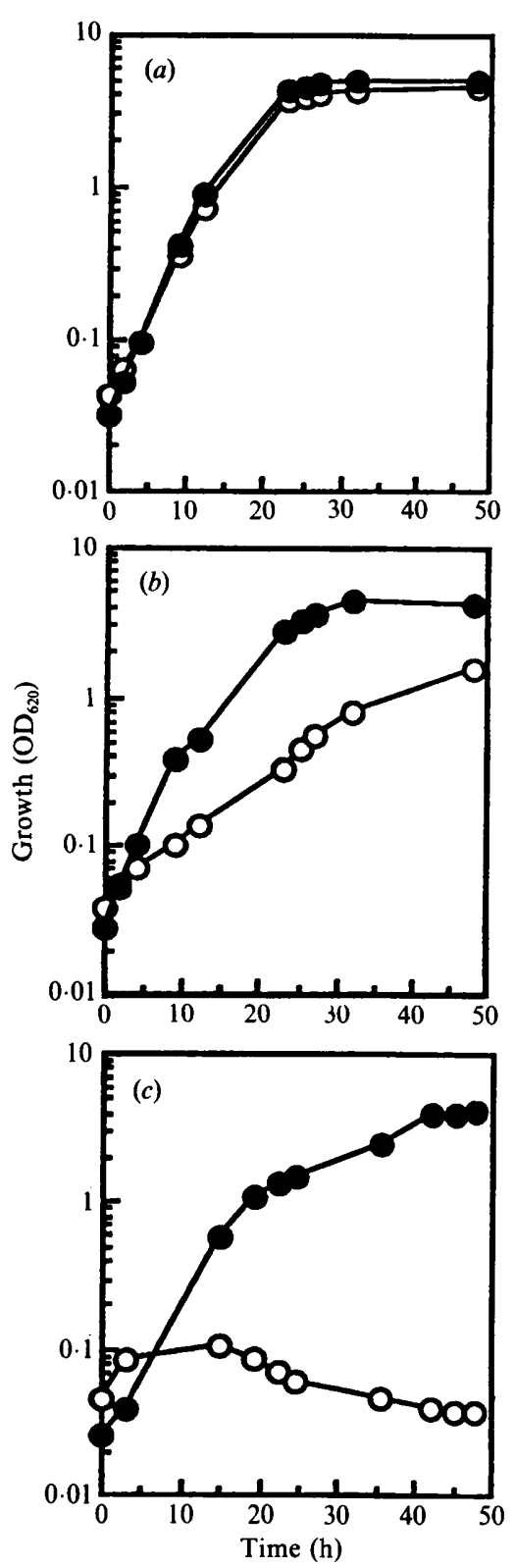

Fig. 1. Growth of the $A$. vinelandii wild-type strain UW $(a)$ and strain P100 $(b, c)$ in iron-sufficient BBGN alone $(\bullet)$ or containing $50 \mu \mathrm{g}$ EDDHA ml-1 $(O) .(a, b)$ Inoculant cells pregrown in BBGN medium; (c) inoculant cells pregrown in OFeBBGN.

the strong chelator of iron EDDHA $\left(50 \mu \mathrm{g} \mathrm{ml}^{-1}\right)$. In the presence of EDDHA, the growth rate of strain P100 was decreased (Fig. 1b). The growth of strain P100 was dependent on the iron content of the medium used to grow the inoculum: when it was pregrown in iron-limited medium (0-1 $\mu \mathrm{M}$-ferric citrate) there was essentially no subsequent growth in the medium containing EDDHA (Fig. 1c). The growth of the other strains in this medium was not adversely affected by prior iron starvation.

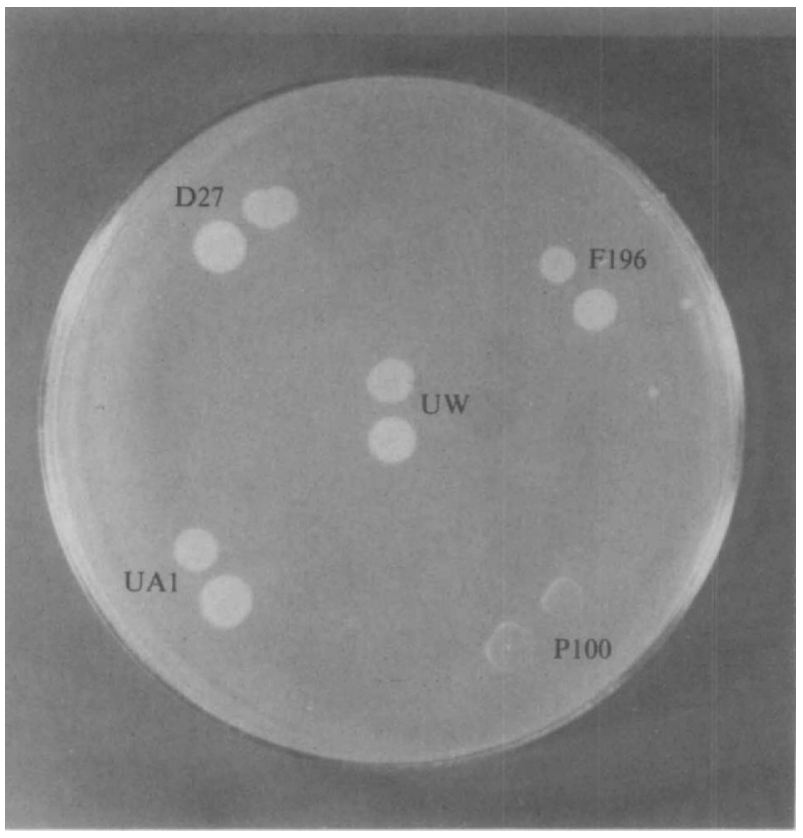

Fig. 2. Reversal of EDDHA inhibition of the growth of strain P100 by siderophores from $A$. vinelandii strains. A plate of $0 \mathrm{FeBBGN}$ containing $50 \mu \mathrm{g}$ EDDHA ml-1 was spotted with $2 \mu 1$ of iron-limited culture of strain P100 (upper spot in each pair) and the siderophoreproducing strains or $\mathrm{P} 100$ as indicated. The plate was incubated for $8 \mathrm{~d}$ at $30^{\circ} \mathrm{C}$.

The inhibitory effect of EDDHA on the growth of strain P100 was also demonstrated on EDDHA-containing plates (Fig. 2). However, on solid medium the growth of strain P100 was only inhibited by EDDHA when the plating medium was OFeBBGN. When the plating medium contained $25 \mu \mathrm{M}$-ferric citrate, strain P100 was able to grow even when the inoculum had been pregrown under iron-limited conditions. Strain P100 could be used in a bioassay for Azotobacter siderophores, as demonstrated by cross-feeding with the other strains on 0FeBBGN medium containing EDDHA (Fig. 2). The inhibition of the growth of strain P100 caused by EDDHA was completely reversed by azotobactin, by the catechol siderophores secreted by the mutants and by the mixture of siderophores secreted by the wild-type strain, but was not reversed by products excreted by strain P100.

\section{Reaction of strain P100 in the CAS assay}

When strain P100 was plated on the CAS medium, a zone of clearing was clearly evident after $24 \mathrm{~h}$ incubation (Fig. 3). This result was unexpected because all the other data had demonstrated that strain P100 was apparently devoid of known siderophore production. The CAS result with strain P100 was possibly due to a non- 


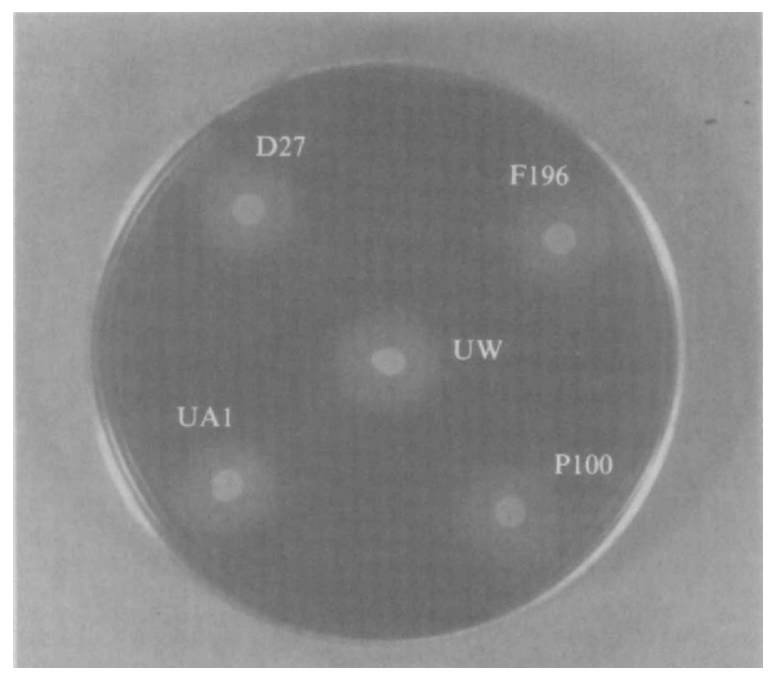

Fig. 3. Siderophore production by wild-type and siderophore-deficient A. vinelandii strains on CAS medium. The plate was spotted with $2 \mu \mathrm{l}$ of inoculum pregrown in BBGN and incubated for $1 \mathrm{~d}$ at $30^{\circ} \mathrm{C}$.

Table 2. Total siderophore activity of strains as estimated by the CAS-shuttle assay

All strains were grown as described in Table 1. Assays were conducted at $37^{\circ} \mathrm{C}$ with unacidified culture supernatant fluids.

\begin{tabular}{lccc}
\hline \hline & \multicolumn{2}{c}{ Total siderophore activity } & \\
\cline { 2 - 3 } Strain & Units* & Specific activity & $\begin{array}{c}\text { End-point } \\
\text { (min) }\end{array}$ \\
\hline UW & 23 & 118 & $1-2$ \\
D27 & 22 & 142 & $1-2$ \\
UA1 & 21 & 104 & $1-2$ \\
F196 & 13 & 75 & $5-6$ \\
P100 & $7 \cdot 1$ & 61 & $\geq 15$ \\
EDDHA & $9 \cdot 1$ & NA & $10-15$ \\
\hline \hline
\end{tabular}

NA, Not applicable.

* Total siderophore activity, where one unit is a $\Delta A_{630}$ of $0.001 \mathrm{~s}^{-1}$.

$\dagger$ Total siderophore specific activity, as units (mg cell protein $)^{-1}$ present in $0.5 \mathrm{ml}$ of culture.

$\ddagger$ EDDHA concentration was $50 \mu \mathrm{g} \mathrm{ml}^{-1}$ in uninoculated medium.

siderophore-mediated decolorization of the ferric-CAS complex, or to the production of a non-conventional siderophore (non-hydroxamate, non-catechol; Schwyn \& Neilands, 1987).

The plating results were confirmed using the spectrophotometric CAS-shuttle assay. The ability of ironlimited culture supernatant fluids to decolorize the ferricCAS complex was followed by measuring the $\Delta A_{630}$ at $10 \mathrm{~s}$ intervals until no further decolorization occurred (Table 2). These data showed that strains UW, D27 and
UAl had about the same total siderophore activity in this assay. The catechol-negative strain F196 had about $60 \%$ of the wild-type activity and strain $\mathrm{P} 100$ had about $30 \%$ of the wild-type activity (Table 2 ). The catecholpositive strains UW, D27 and UA1 recovered ferric iron from the CAS complex very rapidly, whereas the azotobactin-positive strain F196 recovered iron relatively slowly. Strain P100 was the slowest. The deferrating capacity of the putative siderophore in the culture fluid of strain P100 was similar to, but less than that of $50 \mu \mathrm{g}$ EDDHA ml-1 (Table 2); hence EDDHA at this concentration would inhibit the growth of strain P100 (Figs 1 and 2).

The culture fluid of strain P100 was examined for the presence of citric acid, because this has been reported to act as a simple siderophore in Azotobacter salinestris (Page, 1987; Page \& Shivprasad, 1991). However, no detectable citric acid was found in 10-fold concentrated culture fluid of iron-limited strain P100.

\section{Function of the putative siderophore of strain P100}

Strain P100 was incubated in the presence of insoluble iron minerals to determine if the putative siderophore would promote iron uptake. The mineral was contained inside a dialysis bag to eliminate the possibility of mineral adsorption to the cell surface. By definition (Neilands, 1981) a siderophore will be small enough to exchange through the dialysis bag, mobilize the insoluble iron and make it available to the cell. Strain P100 was unable to grow better in the presence of $50 \mathrm{mg} \mathrm{ml}^{-1}$ olivine $\left([\mathrm{Mg}, \mathrm{Fe}]_{2} \mathrm{SiO}_{4}\right)$, haematite $\left(\mathrm{Fe}_{2} \mathrm{O}_{3}\right)$, siderite $\left(\mathrm{FeCO}_{3}\right)$ or goethite $(\mathrm{FeO}[\mathrm{OH}])$ than in 0FeBBGN alone, whereas growth of strain $\mathrm{UW}$ was enhanced in the presence of these insoluble iron sources (data not shown; Page \& Huyer, 1984). However, growth of strain P100 was promoted in the presence of the minerals $\mathrm{FeS}$, vivianite $\left[\mathrm{Fe}_{3}\left(\mathrm{PO}_{4}\right)_{2} .8 \mathrm{H}_{2} \mathrm{O}\right]$, and to a lesser extent $\mathrm{Fe}_{3} \mathrm{O}_{4}$ (Table 3). This growth promotion was paralleled by an increase in cellular iron which was greater than that obtained from the mineral by simple diffusion. Strain P100 was notably less efficient than strain UW in removing iron from these minerals.

Production of the putative siderophore by strain P 100 was repressed by iron. The total siderophore activity of strain P100 in the CAS-shuttle assay was decreased from 59 units (mg protein $)^{-1}$ to 2.8 units (mg protein $)^{-1}$ when the iron content of the medium was increased from $1 \mu \mathrm{M}$ to $25 \mu \mathrm{M}$. Under the same conditions, the total siderophore activity of strain UW decreased from 118 units (mg protein) $)^{-1}$ to 3.5 units (mg protein) $)^{-1}$. Addition of ferric iron to an iron-limited culture supernatant fluid of strain P100 did not result in the formation of a coloured ferric complex or any detectable spectral shift. 
Table 3. Solubilization of iron from iron-containing minerals included in dialysis bags

The data are means \pm standard deviation of two or more duplicates.

\begin{tabular}{|c|c|c|c|c|c|c|c|c|}
\hline \multirow[b]{3}{*}{ Mineral } & \multicolumn{4}{|c|}{ Strain UW } & \multicolumn{4}{|c|}{ Strain P100 } \\
\hline & \multicolumn{2}{|c|}{ Control* } & \multicolumn{2}{|c|}{ With mineral } & \multicolumn{2}{|c|}{ Control $^{*}$} & \multicolumn{2}{|c|}{ With mineral } \\
\hline & $\mathrm{ng} \mathrm{Fe} \mathrm{ml}^{-1} \dagger$ & $\mu \mathrm{g}$ protein $\mathrm{ml}^{-1}$ & $\mathrm{ng} \mathrm{Fe} \mathrm{ml} \mathrm{m}^{-1} \dagger$ & $\mu \mathrm{g}$ protein $\mathrm{ml}^{-1}$ & $\mathrm{ng} \mathrm{Fe} \mathrm{ml} \mathrm{m}^{-1} \dagger$ & $\mu \mathrm{g}$ protein $\mathrm{ml}^{-1}$ & $\mathrm{ng} \mathrm{Fe} \mathrm{ml} \mathrm{m}^{-1} \uparrow$ & $\mu \mathrm{g}$ protein $\mathrm{ml}^{-1}$ \\
\hline None & $9 \cdot 6 \pm 0 \cdot 3$ & $64 \cdot 6 \pm 2 \cdot 4$ & $11.6 \pm 1.9$ & $94.0 \pm 4.7$ & $6 \cdot 1 \pm 0 \cdot 1$ & $50 \cdot 0 \pm 10 \cdot 1$ & $5.9 \pm 1 \cdot 2$ & $53 \cdot 3 \pm 1 \cdot 4$ \\
\hline $\mathrm{Fe}_{3} \mathrm{O}_{4}$ & $10.0 \pm 0.2$ & $70.4 \pm 2.4$ & $113 \pm 7 \cdot 4$ & $741 \pm 32 \cdot 3$ & $10.6 \pm 1.3$ & $50.8 \pm 1.2$ & $34 \cdot 6 \pm 2 \cdot 0$ & $283 \pm 7.2$ \\
\hline Vivianite & $16.4 \pm 0.8$ & $77 \cdot 3 \pm 4 \cdot 0$ & $255 \pm 1.4$ & $817 \pm 17 \cdot 8$ & $16 \cdot 1 \pm 0 \cdot 6$ & $53.2 \pm 3.5$ & $105 \pm 1.4$ & $505 \pm 9.8$ \\
\hline $\mathrm{FeS}$ & $22.0 \pm 1.4$ & $204 \pm 5.9$ & $651 \pm 7.8$ & $934 \pm 12 \cdot 5$ & $15.9 \pm 0.9$ & $94.9 \pm 4.7$ & $192 \pm 4.8$ & $606 \pm 11.4$ \\
\hline
\end{tabular}

* Freely exchangeable iron control culture.

$\dagger$ Cellular iron accumulation.

$\ddagger \mathrm{Fe}_{3}\left(\mathrm{PO}_{4}\right)_{2} .8 \mathrm{H}_{2} \mathrm{O}$.

Table 4. Comparison of the nitrogen-fixing growth of siderophore-negative strains at high aeration

Cultures were incubated at $28{ }^{\circ} \mathrm{C}$ with shaking at 300 r.p.m. in baffle flasks, in Burk's nitrogen-free medium containing 0,1 and $25 \mu \mathrm{M}$-iron. Growth rates were determined from plots of turbidity $\left(\mathrm{OD}_{620}\right)$ versus time during the exponential growth phase from 0 to $18 \mathrm{~h}$.

\begin{tabular}{|c|c|c|c|c|c|c|c|}
\hline \multirow[b]{2}{*}{ Strain } & \multicolumn{3}{|c|}{ Doubling time $(\mathrm{h})$} & \multicolumn{4}{|c|}{ Siderophores in iron-sufficient culture* } \\
\hline & $0 \mu \mathrm{M}-\mathrm{Fe}$ & $1 \mu \mathrm{M}-\mathrm{Fe}$ & $25 \mu \mathrm{M}-\mathrm{Fe}$ & Hydroxamate $\dagger$ & Catecholf & CAS (AQ)§ & CAS (EA)§ \\
\hline UW & $3 \cdot 1$ & 2.7 & $3 \cdot 1$ & 0 & 10 & + & + \\
\hline D27 & $4 \cdot 0$ & 3.0 & $3 \cdot 2$ & 0 & 11 & + & + \\
\hline UAl & $4 \cdot 0$ & $3 \cdot 0$ & $3 \cdot 1$ & 0 & 12 & + & + \\
\hline F196 & $3 \cdot 5$ & $2 \cdot 7$ & 2.9 & 0.05 & 0 & + & - \\
\hline P100 & $4 \cdot 6$ & 3.4 & 3.5 & 0 & 0 & + & - \\
\hline
\end{tabular}

* Iron-sufficient medium contained $25 \mu \mathrm{M}$-iron and was harvested at $24 \mathrm{~h}$.

$\dagger$ Hydroxamate was determined as the $A_{380}$ of acidified culture fluid.

$\ddagger$ Catechol was determined as the concentration of catechol $(\mu \mathrm{M})$ according to the assay of Barnum (1977).

$\S \mathrm{CAS}$ assay results using the aqueous phase after ethyl acetate extraction (CAS-AQ) or the ethyl acetate extract (CAS-EA) of 10-fold concentrated iron-sufficient culture supernatant fluids. A positive result was indicated by a decrease in $A_{630}$ of $\geq 5$ units (according to Table 2) which continued for at least $120 \mathrm{~s}$. A negative result was no net decrease in $A_{630}$ over $120 \mathrm{~s}$.

\section{Aerobic nitrogen-fixing growth of strain P100}

The growth of strain P100 was significantly impaired compared to strain UW under highly aerobic nitrogenfixing conditions (Table 4). In OFeBBG, the growth of strain P100 was the slowest, followed by the azotobactinnegative strains. As the iron content of the medium was increased to $1 \mu \mathrm{M}$, the growth rate of all the strains increased, but the pattern of growth rates remained the same. A further increase in iron concentration to $25 \mu \mathrm{M}$ did not increase the growth rate of strain P100 to a value comparable with the wild-type strain. In this iron-sufficient medium the catechol-producing strains released about $11 \mu \mathrm{M}$-2,3-DHBA into the culture fluid and strain F196 always released a small amount of azoto- bactin. Examination of 10 -fold concentrated culture supernatant fluids revealed that all of the strains produced siderophore activity according to the CASshuttle assay. This was attributed to small amounts of catechol siderophores produced by all catechol-positive strains, a small amount of azotobactin produced by the wild-type, definite azotobactin production by strain F196 and non-conventional siderophore production by strain P100. 2,3-DHBA alone $(0.5 \mathrm{ml}$ of $500 \mu \mathrm{M})$ did not give a positive result in the CAS-shuttle assay. The final amount of cell protein $\left(\mu \mathrm{g} \mathrm{ml}^{-1}\right)$ produced by strains F196, D27, UA1 and P100 in this iron-sufficient medium was $80,75,75$ and $72 \%$ of that produced by the wild-type strain. 


\section{Discussion}

It appeared that $\boldsymbol{A}$. vinelandii produces another siderophore in addition to the known catechol and pyoverdin siderophores. This compound functioned as a siderophore: it promoted iron accumulation from insoluble iron sources, it promoted cell growth under iron-limited conditions and its production was repressed by iron. The siderophore appeared to be a non-conventional one, in that it lacked hydroxamate or catechol groups and was only detectable in the CAS assay of Schwyn \& Neilands (1987). Other non-conventional siderophores have been detected using the CAS assay, for example citric acid produced by Bradyrhizobium japonicum (Guerinot et al., 1990), rhizobactin produced by Rhizobium meliloti (Schwyn \& Neilands, 1987), and staphyloferrin produced by Staphylococcus spp. (Meiwes et al., 1990), which all coordinate iron by carboxylic acid groups. The nonconventional $\boldsymbol{A}$. vinelandii siderophore is not citric acid and citric acid does not promote iron uptake into $A$. vinelandii (Knosp et al., 1984). While the structure of the $A$. vinelandii non-conventional siderophore is unknown, it did appear to be a relatively low-affinity chelator that remained in the aqueous phase after ethyl acetate extraction. The siderophore did not reverse the inhibition caused by $50 \mu \mathrm{g}$ EDDHA $\mathrm{ml}^{-1}$ and only solubilized iron from the most soluble minerals tested. Previous studies have shown that the iron in FeS and vivianite can be solubilized by 2,3-DHBA alone at neutral $\mathrm{pH}$, but utilization of the iron from $\mathrm{Fe}_{3} \mathrm{O}_{4}$ requires the induction of the catechol siderophores (Page \& Huyer, 1984). The catechol siderophores of $\boldsymbol{A}$. vinelandii are low-affinity chelators capable of bidentate or tetradentate coordination of iron (Page \& von Tigerstrom, 1988). It is interesting that attempts to reconstruct the total siderophore activity of the ironlimited $A$. vinelandii culture supernatant fluid, by mixing appropriate portions of catechol and azotobactin siderophores, has never resulted in $100 \%$ of the original activity (Knosp et al., 1984; Page \& von Tigerstrom, 1988; W. J. Page \& M. von Tigerstrom, unpublished data). It would now appear that this was because not all the siderophores had been identified.

The success of the growth of strain P100 under ironstress conditions was affected by the iron status of the medium used for the production of the inoculum. $A$. vinelandii is known to produce bacterioferritin (Jiudi $e t$ al., 1990; Steifel \& Watt, 1979) and this iron reserve was apparently sufficient to promote the growth of strain P100 under conditions where exogenous iron uptake was minimal. Iron-starved cells of strain $\mathrm{P} 100$ were unable to grow well under nitrogen-fixing conditions at high aeration, presumably because the low-affinity nonconventional siderophore was unable to scavenge the small amount of iron present in this medium. The growth rate of strain $\mathrm{P} 100$ did increase when $1 \mu \mathrm{M}$-iron was available in the medium, presumably as a result of iron mobilization by the unconventional siderophore, but the growth rate did not increase further when $25 \mu \mathrm{M}$-iron was present. Both strain P100 and the wild-type should demonstrate the same siderophore-independent growth rate under these iron-sufficient conditions, as was observed with the other siderophore-deficient strains. The results showed that all the strains produced very low levels of siderophores under these conditions, which indicated that the iron in the medium must not have been freely available. Thus growth of strain P100 would be retarded according to the affinity of its siderophore for iron under these iron-stress conditions. Low-level siderophore production in $\mathrm{B} 6$ medium containing $25 \mu \mathrm{M}-\mathrm{FeSO}_{4}$ was also observed by Fekete et al. (1983), when $A$. vinelandii was grown in continuous culture at high aeration. It has been shown that $50 \mu \mathrm{M}$-nitrilotriacetate, 10-fold more than used by Fekete et al. (1983), has to be added to B6 medium to keep the iron soluble under aerobic chemostat conditions (Partridge \& Yates, 1982).

Very little has been published concerning the genetic organization and regulation of the gene products responsible for the synthesis of $A$. vinelandii siderophores. While this present study did not generate a great variety of easily identifiable phenotypes, it does demonstrate several interesting points. A single $\mathrm{Tn} 5$ insertion in strain F196 has inactivated the production of all known catechol siderophores, including 2,3-DHBA. This suggests that the biosynthetic genes for catechol siderophores may be organized in an operon. Alternatively, the biosynthesis of 2,3-DHBA may be a prerequisite for catechol siderophore synthesis, analogous to the requirement for the ent $A$, ent $B$ and ent $C$ gene products in enterobactin biosynthesis (Ozenberger et al., 1989). However, exogenous 2,3-DHBA did not overcome the mutation in strain F196 and promote catechol siderophore biosynthesis. It also appeared that 2,3-DHBA synthesis was iron-repressible. Thus, the apparent constitutive production of 2,3-DHBA (Page \& Huyer, 1984) must have been a result of the difficulty in maintaining freely soluble iron in highly aerated medium, not due to unregulated transcription.

Glick et al. (1988) used chemical mutagenesis to generate $A$. vinelandii mutants defective in siderophore synthesis. They found that strains defective in azotobactin synthesis $\left(\mathrm{Flu}^{-}\right)$were common, but most of these mutants were also defective in catechol siderophore synthesis and some also lacked IROMPs. In addition, mutant strains that lacked both azotobactin and azotochelin production were siderophore-negative in the CAS assay. Glick et al. (1988) concluded that siderophore synthesis in $A$. vinelandii was highly integrated and that 
the synthesis of azotobactin and azotochelin was functionally coupled. The results of the present study showed that azotobactin-negative and catechol-negative mutants can be generated independently and that the loss of azotobactin does not affect the level of catechol siderophore production.

Obtaining and maintaining mutants of $\boldsymbol{A}$. vinelandii has been a problem for years (Kennedy \& Toukdarian, 1987 ), due to the extreme polyploidy of this prokaryote. The organism has $\geq \mathbf{4 0}$ copies of its chromosome (Punita et al., 1989; Sadoff et al., 1979), which segregate randomly during cell division (Phadnis et al., 1988). Thus the selection of stable recessive mutations requires many generations to ensure that a homozygous cell is produced, at the price of losing mutations by repair or through dilution (Phadnis et al., 1988). Transposon mutagenesis provides a means of introducing single insertions and a selective pressure (antibiotic resistance), to promote the formation of a homozygous mutant cell (Kennedy \& Toukdarian, 1987; Phadnis et al., 1988). It is highly likely that the chemical mutagenesis used by Glick et al. (1988) generated multiple mutations and that their conclusions are thus not valid. However, in this study it was observed that a loss of catechol siderophores did increase the level of azotobacin produced. This may relate to the functional role of these siderophores, rather than to linked transcription. The lower-affinity catechol siderophores appear to be efficient solubilizers of mineral iron sources, while azotobactin appears to be a scavenger of soluble iron (Page \& Huyer, 1984; Page \& von Tigerstrom, 1988). Only when the amount of catechol siderophores produced in $0 \mathrm{FeBBGN}$ fails to liberate iron from insoluble minerals, is azotobactin hyperproduced. Thus catechol-siderophore-negative cells may sense that they are iron-limited, even though mineral iron is present. Under these conditions, azotobactin is produced, soluble iron is scavenged and iron-limited growth is promoted, resulting in enhanced azotobactin production.

It is clear that $A$. vinelandii has developed elaborate systems for iron acquisition, attesting to the importance of this micronutrient. However, the majority of the ironrepressible mutants generated in this study were not identified as being defective in siderophore production or iron uptake. Iron limitation of $\boldsymbol{A}$. vinelandii is known to enhance capsule formation (Jarman et al., 1978), to enhance encystment (Layne \& Johnson, 1964) and to induce genetic transformation competence (Page \& von Tigerstrom, 1978). Further characterization of these mutant strains and identification of the non-conventional siderophore is in progress.

We thank Dena Adachi for technical assistance. This study was supported by a grant to W.J.P. from the Natural Sciences and Engineering Research Council of Canada.

\section{References}

BARNUM, D. W. (1977). Spectrophotometric determination of catechol, epinephrine, DOPA, dopamine and other aromatic vic-diols. Analytica Chimica Acta 89, 157-166.

Berg, C. M., Berg, D. E. \& Grolsman, E. A. (1989). Transposable elements and genetic engineering in bacteria. In Mobile DNA, pp. 879-925. Edited by D. E. Berg \& M. M. Howe. Washington, DC: American Society for Microbiology.

Collinson, S. K., Doran, J. L. \& Page, W. J. (1987). Production of 3,4-dihydroxybenzoic acid by Azomonas macrocytogenes and Azotobacter paspali. Canadian Journal of Microbiology 33, 169-175.

CORBIN, J. L. \& BULEN, W. A. (1969). The isolation and identification of 2,3-dihydroxybenzoic acid and 2-N,6-N-di(2,3-dihydroxybenzoyl)-L-lysine formed by iron-deficient Azotobacter vinelandii. Biochemistry 8, 757-762.

Cox, C. D. (1989). Importance of iron in bacterial virulence. In Metal Ions and Bacteria, pp. 207-246. Edited by T. J. Beveridge \& R. J. Doyle. New York: John Wiley.

CSAKY, T. Z. (1948). On the estimation of bound hydroxylamine in biological materials. Acta Chemica Scandinavica 2, 450-454.

Demange, P., Wendenbaum, S., Bateman, A., Dell, A., Meyer, J. M. \& ABDALLAH, M. A. (1986). Bacterial siderophores: structure of pyoverdins and related compounds. In Iron, Siderophores, and Plant Diseases, pp. 131-147. Edited by T. R. Swinburne. New York: Plenum Press.

Doran, J. L., Bingle, W. H., Roy, K. H., Hiratsuka, K. \& Page, W. J. (1987). Plasmid transformation of Azotobacter vinelandii OP. Journal of General Microbiology 133, 2059-2072.

Fekete, F. A., SPEnce, J. T. \& Emery, T. (1983). Siderophores produced by nitrogen-fixing Azotobacter vinelandii OP in iron-limited continuous culture. Applied and Environmental Microbiology 46, 1297-1300.

FIGURSKI, O. H. \& HeLINSKI, D. R. (1979). Replication of an origincontaining derivative of plasmid RK2 depedent on a plasmid function provided in trans. Proceedings of the National Academy of Sciences of the United States of America 76, 1648-1652.

Filip, C., Fletcher, G., WulfF, J. L. \& Earhart, C. F. (1973). Solubilization of the cytoplasmic membrane of Escherichia coli by the ionic detergent sodium-lauryl sarcosinate. Journal of Bacteriology 115, 717-722.

Glick, B. R., Menhart, N., Soong, N. W., Farmer, W. H., Viswanatha, T. \& Pasternak, J. J. (1988). Isolation and partial characterization of siderophore mutants of Azotobacter vinelandii. Current Microbiology 17, 343-346.

Guerinot, M. L., MeidL, E. J. \& Plessner, O. (1990). Citrate as a siderophore in Bradyrhizobium japonicum. Journal of Bacteriology 172, 3298-3303.

Jarman, T. R., Deavin, L., Slocombe, S. \& Righelato, R. C. (1978). Investigation of the effect of environmental conditions on the rate of exopolysaccharide synthesis in Azotobacter vinelandii. Journal of General Microbiology 107, 59-64.

JiUd, L., JiWEN, W., ZEPU, Z., YA, T. \& BeI, D. (1990). Presence of a cytochrome $b$-containing ferritin in Azotobacter vinelandii. Scientia Sinica 23, 897-904.

JURTSHUK, P., JR, LIU, J.-K. \& MoORE, E. R. B. (1984). Comparative cytochrome oxidase and superoxide dismutase analyses on strains of Azotobacter vinelandii and other related free-living nitrogen-fixing bacteria. Applied and Environmental Microbiology 47, 1185-1187.

KeNNEDY, C. \& TouKDARIAN, A. (1987). Genetics of azotobacters: applications to nitrogen fixation and related aspects of metabolism. Annual Review of Microbiology 41, 227-258.

KNosP, O., von Tigerstrom, M. \& PAGe, W. J. (1984). Siderophoremediated uptake of iron in Azotobacter vinelandii. Journal of Bacteriology 159, 341-347.

KREBS, K. G., HeUSSER, D. \& Wimmer, H. (1969). Spray reagents. In Thin Layer Chromatography, pp. 854-909. Edited by E. Stahl. New York: Springer-Verlag.

LAYNE, J. S. \& Johnson, E. J. (1964). Natural factors involved in the induction of cyst formation in Azotobacter. Journal of Bacteriology 87 , 684-689. 
de Lorenzo, V., Wee, S., Herrero, M. \& Neilands, J. B. (1987). Operator sequences of the aerobactin operon of plasmid ColV-K30 binding the ferric uptake regulation (fur) repressor. Journal of Bacteriology 169, 2624-2630.

MCINTOSH, M. A. \& EARHART, C. F. (1977). Coordinate regulation by iron of the synthesis of phenolate compounds and three outer membrane proteins in Escherichia coli. Journal of Bacteriology 131, 331-339.

Meiwes, J., Fiedler, H.-P., HaAg, H., Zahner, H., KonetschnyRAPP, S. \& JUNG, G. (1990). Isolation and characterization of staphyloferrin A, a compound with siderophore activity from Staphylococcus hyicus DSM 20459. FEMS Microbiology Letters 67, 201-206.

NeILANDS, J. B. (1981). Microbial iron compounds. Annual Review of Biochemistry 50, 715-731.

NeILANDS, J. B. (1982). Microbial envelope proteins related to iron. Annual Review of Microbiology 36, 285-309.

Ozenberger, B. A., Brickman, T. J. \& McIntosh, M. A. (1989). Nucleotide sequence of Escherichia coli isochorismate synthetase gene entC and evolutionary relationship of isochorismate synthetase and other chorismate-utilizing enzymes. Journal of Bacteriology 171, 775-783.

PAGE, W. J. (1987). Iron-dependent production of hydroxamate by sodium-dependent Azotobacter chroococcum. Applied and Environmental Microbiology 53, 1418-1424.

PAGE, W. J. \& HUYeR, M. (1984). Derepression of the Azotobacter vinelandii siderophore system using iron-containing minerals to limit iron repletion. Journal of Bacteriology 158, 496-502.

Page, W. J. \& Patrick, J. (1988). The DNA gyrase inhibitors, nalidixic acid and oxolinic acid, prevent iron-mediated repression of catechol siderophore synthesis in Azotobacter vinelandii. Biology of Metals 1, 57-61.

PaGe, W. J. \& Shivprasad, S. (1991). Azotobacter salinestris sp. nov., a sodium-dependent, microaerophilic, and aeroadaptive nitrogenfixing bacterium. International Journal of Systematic Bacteriology 41 , 369-376.

PAGE, W. J. \& VON TIgerstrom, M. (1978). Induction of transformation competence in Azotobacter vinelandii iron-limited cultures. Canadian Journal of Microbiology 24, 1590-1594.

Page, W. J. \& Von Tigerstrom, M. (1979). Optimal conditions for transformation of Azotobacter vinelandii. Journal of Bacteriology 139, 1058-1061.
Page, W. J. \& VoN Tigerstrom, M. (1982). Iron- and molybdenumrepressible outer membrane proteins in competent Azotobacter vinelandii. Journal of Bacteriology 151, 237-242.

PAGE, W. J. \& vON TIGerstrom, M. (1988). Aminochelin, a catecholamine siderophore produced by Azotobacter vinelandii. Journal of General Microbiology 134, 453-460.

Page, W. J., Collinson, S. K., Demange, P., Dell, A. \& Abdallah, M. A. (1991). Azotobacter vinelandii strains of disparate origin produce azotobactin siderophores with identical structures. Biology of Metals 4, 217-222.

PARTRIDGe, C. D. P. \& YATES, M. G. (1982). Effect of chelating agents on hydrogenase in Azotobacter chroococcum. Biochemical Journal 204, 339-344.

Phadnis, S. H., Dimiri, G. P. \& Das, H. K. (1988). Segregation characteristics of multiple chromosomes of Azotobacter vinelandii. Journal of Genetics 67, 37-42.

Punita, S. J., Reddy, M. A. \& Das, H. K. (1989). Multiple chromosomes of Azotobacter vinelandii. Journal of Bacteriology 171, 3133-3138.

Robson, R. L. \& Postgate, J. R. (1980). Oxygen and hydrogen in biological nitrogen fixation. Annual Review of Microbiology 34, 183-207.

SADOFF, H. L., Shimei, B. \& Ellis, S. (1979). Characterization of Azotobacter vinelandii deoxyribonucleic acid and folded chromosomes. Journal of Bacteriology 138, 871-877.

SchWYN, B. \& NeILANDS, J. B. (1987). Universal chemical assay for detection and determination of siderophores. Analytical Biochemistry $160,47-56$.

SelveraJ, G. \& IYer, V. N. (1983). Suicide plasmid vehicles for insertion mutagenesis in Rhizobium meliloti and related bacteria. Journal of Bacteriology 156, 1292-1300.

STEIFEL, E. I. \& WATT, G. D. (1979). Azotobacter cytochrome $b_{557.5}$ is a bacterioferritin. Nature, London 279, 81-83.

WiLson, K. (1990). Preparation of genomic DNA from bacteria. In Current Protocols in Molecular Biology, vol. 1, Supplement 9, pp. 2.4.1-2.4.5. Edited by F. M. Ausubel, R. Brent, R. E. Kingston, D. D. Moore, J. G. Seidman, J. A. Smith \& K. Struhl. New York: John Wiley.

WraY, W., Boulikas, T., Wray, V. P. \& HaNCOCK, R. (1981). Silver staining of proteins in polyacrylamide gels. Analytical Biochemistry 118, 197-203. 